\title{
The endoscopic endonasal approach to the odontoid and its impact on early extubation and feeding
}

\author{
Tony Goldschlager, MBBS, PhD, FRACS, ${ }^{1,4,5}$ Roger Härtl, MD, ${ }^{1}$ Jeffrey P. Greenfield, MD, PhD, ${ }^{1}$ \\ Vijay K. Anand, MD, ${ }^{2}$ and Theodore H. Schwartz, MD ${ }^{1-3}$
}

\begin{abstract}
Departments of ${ }^{1}$ Neurosurgery, ${ }^{2}$ Otorhinolaryngology, and ${ }^{3}$ Neurology, Weill Cornell Medical College, Sackler Brain and Spine Center, NewYork-Presbyterian Hospital, New York, New York; ${ }^{4}$ Department of Neurosurgery, Monash Health; and ${ }^{5}$ Department of Surgery, Monash University, Melbourne, Australia
\end{abstract}

\begin{abstract}
OBJECT The gold-standard surgical approach to the odontoid is via the transoral route. This approach necessitates opening of the oropharynx and is associated with risks of infection, and swallowing and breathing complications. The endoscopic endonasal approach has the potential to reduce these complications as the oral cavity is avoided. There are fewer than 25 such cases reported to date. The authors present a consecutive, single-institution series of 9 patients who underwent the endonasal endoscopic approach to the odontoid.
\end{abstract}

METHODS The charts of 9 patients who underwent endonasal endoscopic surgery to the odontoid between January 2005 and August 2013 were reviewed. The clinical presentation, radiographic findings, surgical management, complications, and outcome, particularly with respect to time to extubation and feeding, were analyzed. Radiographic measurements of the distance between the back of the odontoid and the front of the cervicomedullary junction (CMJ) were calculated, as well as the location of any residual bone fragments.

RESULTS There were 7 adult and 2 pediatric patients in this series. The mean age of the adults was 54.8 years; the pediatric patients were 7 and 14 years. There were 5 females and 4 males. The mean follow-up was 42.9 months. Symptoms were resolved or improved in all but 1 patient, who had concurrent polyneuropathy. The distance between the odontoid and CMJ increased by $2.34 \pm 0.43 \mathrm{~mm}(p=0.03)$. A small, clinically insignificant fragment remained after surgery, always on the left side, in $57 \%$ of patients. Mean times to extubation and oral feeding were on postoperative Days 0.3 and 1, respectively. There was one posterior cervical wound infection; there were 2 cases of epistaxis requiring repacking of the nose and no instances of breathing or swallowing complications or velopharyngeal insufficiency.

CONCLUSIONS This series of 9 cases of endonasal endoscopic odontoidectomy highlights the advantages of the approach in permitting early extubation and early feeding and minimizing complications compared with transoral surgery. Special attention must be given to bone on the left side of the odontoid if the surgeon is standing on the right side.

http://thejns.org/doi/abs/10.3171/2014.9.JNS14733

KEY WORDS cervicomedullary junction; endonasal; endoscopy; extubation; feeding; odontoid; odontoidectomy; transnasal; transsphenoidal; anatomy

$\mathrm{A}$ RECENT paper by Choi and Crockard compared transoral odontoid surgery to the crocodile; it has persisted from prehistoric times but still has a place today. ${ }^{5}$ Indeed, the transoral approach is considered the gold-standard approach to surgically address periodontoid pathology. ${ }^{16}$ However, the evolution of endoscopic endonasal surgery has led to the development of a minimally invasive alternative approach to the odontoid. While both the transoral and endonasal approaches are "natural orifice" surgery, the biggest advantage of the endonasal en- doscopic approach arises from the location of the mucosal incision in the nasopharynx and not the oropharynx. In theory, minimizing disruption of the oropharynx allows patients to be extubated and to begin oral feeding sooner, thereby reducing the length of stay and the complications that may arise from prolonged intubated and delayed feeding. ${ }^{20}$ Likewise, the palate does not need to be split, as is sometimes the case with transoral surgery. However, few cases have been reported in the literature to support this claim. 
A recent meta-analysis was performed to assess the role of the endonasal endoscopic approach and compare it to the transoral approach. ${ }^{20}$ While the meta-analysis did show advantages of the endonasal approach, it was limited by small numbers. The present study reports on a consecutive series of patients from a single center, operated on by the same surgical team, who underwent endoscopic endonasal approaches to the odontoid. The results add significantly to the number of patients reported on in the literature and document markedly earlier extubation and feeding than previously reported.

\section{Methods}

A prospective database of all endoscopic skull base surgeries performed at Weill Cornell Medical College, NewYork-Presbyterian Hospital, between January 2005 and August 2013, was retrospectively reviewed. Institutional review board approval was obtained for this study. Patients who underwent an endoscopic endonasal approach to the odontoid were included, and their hospital and clinic records were reviewed.

The following data were collected: demographic information (including patient age and sex), presenting complaint, operative diagnosis, operative details, blood loss, operative time, time to extubation, time to resumption of oral feeding, length of stay, complications, adjuvant operations (including posterior fusion and/or decompression), and status at follow-up. To quantify the efficacy of the technique, we measured the amount of T2 signal in front of the cervicomedullary junction (CMJ) at the level of the odontoid before and after surgery on MRI (when available). The measurement was taken at the area of greatest compression or closest proximity between the odontoid and the CMJ. This was done by 2 separate neurosurgeons, and the average of the 2 measurements was used for calculations. The postoperative CT scans were reviewed and the location of residual odontoid, if any, was recorded. Paired nonparametric statistics were used to determine significance.

\section{Surgical Technique}

All operations were performed by a surgical team that included an otolaryngologist (V.K.A.) and a neurosurgeon (T.H.S.) at the Institute for Minimally Invasive Skull Base and Pituitary Surgery, Weill Cornell Medical College, NewYork-Presbyterian Hospital. In cases in which a posterior fusion was indicated this was performed by a spinal neurosurgeon (R.H.). Pediatric procedures were performed in conjunction with a pediatric neurosurgeon (J.P.G.).

The details of the surgery are described elsewhere ${ }^{10,21}$ (Fig. 1). Most patients underwent posterior fusion prior to endonasal odontoid resection, either on a previous day or the same day in the morning. Since endonasal odontoid resection destabilizes C- 1 and $\mathrm{C}-2$, we elected to perform the fusion first to minimize the hypothetical risk of cord injury that might occur after endonasal surgery during patient position for a posterior fusion. Some patients were placed in a halo for subsequent posterior fusion.

In brief, after oropharyngeal intubation, prophylactic antibiotics and dexamethasone were administered. The patient was placed supine on the operating table with the head secured in the Mayfield 3-pin headrest, and registration of the frameless stereotactic system was performed. Preoperative CT scans of the CMJ were used for navigation, sometimes coregistered with MRI. Motor evoked potentials and somatosensory evoked potentials were used throughout most procedures. The inferior turbinates were lateralized bilaterally, and a submucosal resection of the posterior $2 \mathrm{~cm}$ of the septal cartilage was performed using a tissue shaver and a high-speed drill to enlarge the choana for a wider exposure. A 30-cm, 4-mm rigid $0^{\circ}$ endoscope (Karl Storz) was held in the left nostril with an endoscope holder, and surgery was performed using a bimanual technique either through the right or both nostrils as required. The operative surgeon stands on the right side of the patient (Fig. 1).

A red rubber catheter was placed through the nasal cavity into the oral cavity for downward retraction of the soft palate to facilitate exposure. The fascia of the posterior nasopharynx was opened with an inverted U-shaped or linear incision. The longus colli and capitis muscles were elevated bilaterally using monopolar diathermy. Under stereotactic guidance, the inferior portion of the clivus was removed to expose the basilar tip depending on the degree of invagination. Then the anterior ring of C-1 was removed. Finally, the odontoid was resected by internal decompression with a high-speed drill and removal of the lateral and superior rim with a curette. If significant inflammatory pannus was present behind the odontoid, the ultrasonic aspirator and a Kerrison rongeur were used to remove the pannus and transverse ligament to expose the dura. The nasopharyngeal flap was then reapproximated and held in place with TISSEEL (Baxter). Floseal hemostatic matrix (Baxter) was then placed in the nasopharynx. Intraoperative imaging was only used in one case to determine the extent of resection as it is not routinely available at our institution. Follow-up was performed by the neurosurgeons involved and the otolaryngologist. The otolaryngologist performed office-based endoscopic assessment of nasal and pharyngeal function to monitor for complications.

\section{Results}

\section{Demographics}

There were 7 adult and 2 pediatric patients in this series. Three of these cases (Cases 1,2, and 3) were previously published as case reports. ${ }^{10,21,22}$

The mean age of the adults was 54.8 years \pm 8.3 years (range 20-77 years). The pediatric patients were 7 and 14 years old. There were 5 females and 4 males. A summary of patient characteristics is shown in Table 1. The average follow-up was 42.9 months (range 1.3-99.1 months).

\section{Patient Presentation and Diagnosis}

Neck pain was the most common presenting complaint, occurring in 56\% of patients. This occurred in isolation or in conjunction with other complaints, such as cervical myelopathy and swallowing difficulty, both of which occurred in $44 \%$ of patients. The patient in Case 2 presented with neck pain but had significant cervicomedullary com- 

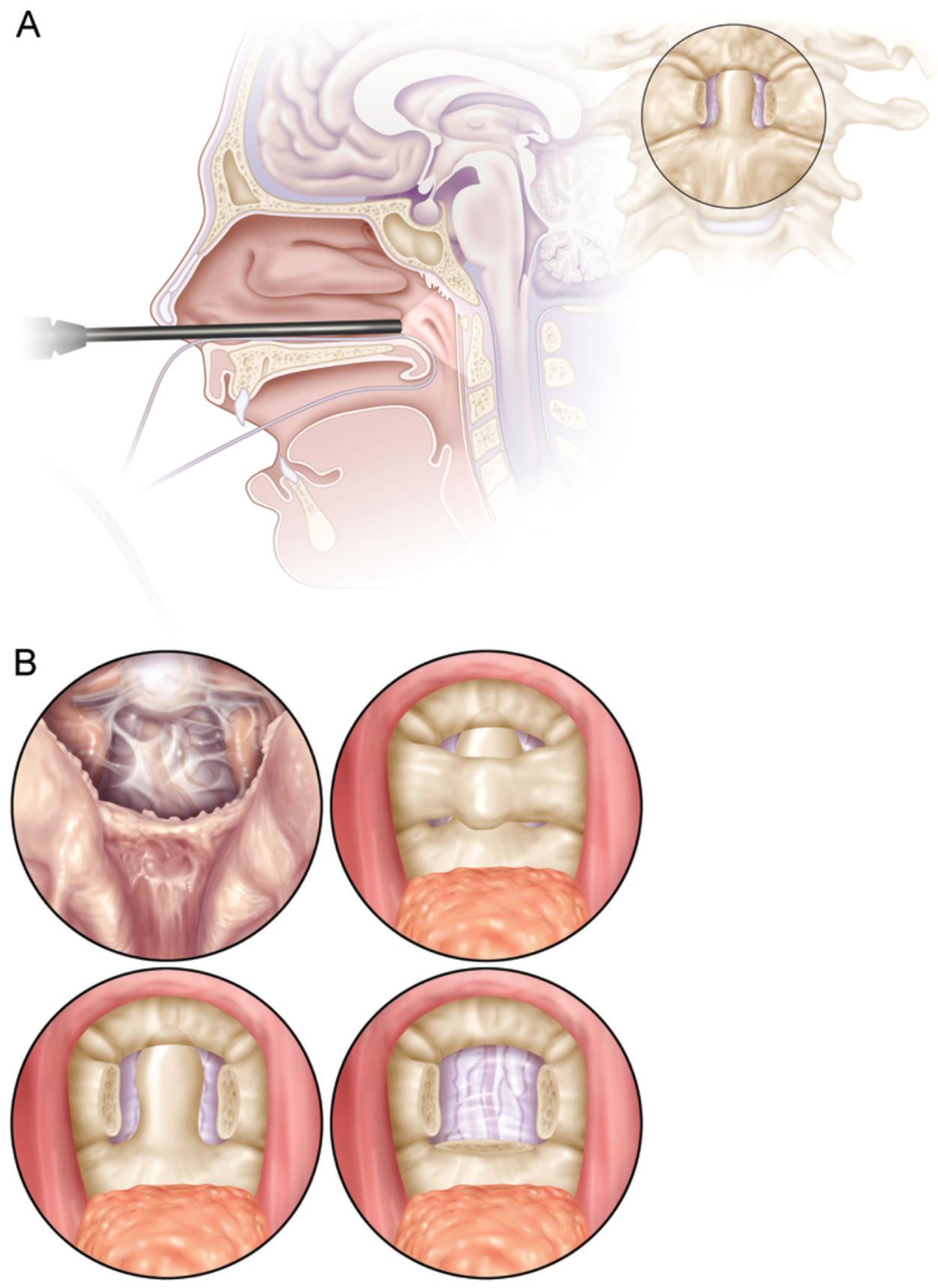

FIG. 1. A: Illustration showing the endoscopic endonasal approach to the odontoid along the hard palate. Note the absence of trauma to the oropharynx, which facilitates early extubation and feeding. Inset: View of the odontoid, after removal of the anterior ring of C-1. B: Staged views of operation. Upper Left: The nasopharyngeal fascia between the eustachian tubes overlies the bottom of the clivus and the top of the odontoid. The sphenoid sinus is opened here for orientation purposes but does not need to be opened in this operation. Upper Right: Anterior arch of C-1 after removal of nasopharyngeal fascia and longus colli muscles. Lower Left: Odontoid process following removal of anterior arch of C-1. Lower Right: Ventral dura in front of CMJ following odontoid removal. Copyright Holt Medical Illustration. Published with permission. Figure is available in color online only.

pression from a combination of basilar invagination and rheumatoid pannus. Both pediatric patients had cerebellar signs on presentation and had a diagnosis of basilar invagination and Chiari malformation. Basilar invagination was present in $43 \%$ of adults, which was associated with rheumatoid arthritis and odontoid pannus in 2 cases. The diagnoses in the remaining patients were mass lesions secondary to gout, a ganglion cyst, os odontoideum and a breast metastasis. Individualized details are shown in Table 1 .

\section{Timing of Fusion}

All patients who underwent odontoidectomy had supplemental posterior instrumented fusion. This varied be- 
TABLE 1. Patient demographics, presentation, diagnosis, and follow-up

\begin{tabular}{|c|c|c|c|c|}
\hline $\begin{array}{l}\text { Case } \\
\text { No. }\end{array}$ & $\begin{array}{c}\text { Age } \\
\text { (yrs), } \\
\text { Sex }\end{array}$ & $\begin{array}{c}\text { Presenting } \\
\text { Symptoms \& Signs }\end{array}$ & Diagnosis & Follow-Up \\
\hline $1^{*}$ & $71, \mathrm{M}$ & NP & Gout & Resolved \\
\hline $2^{*}$ & $32, \mathrm{M}$ & NP & $\begin{array}{l}\text { Juvenile RA, pannus, basilar invagination, } \\
\text { cervicomedullary compression }\end{array}$ & Improved \\
\hline $3^{*}$ & $50, \mathrm{~F}$ & $\mathrm{CM}$ & Os odontoideum & Improved \\
\hline 4 & $59, \mathrm{~F}$ & SD & Breast metastasis & Resolved \\
\hline 5 & $14, \mathrm{M}$ & CS, CM, SD & Basilar invagination, Chiari malformation & CM, SD resolved; CS improved \\
\hline 6 & $77, \mathrm{~F}$ & $\mathrm{NP}, \mathrm{CM}$ & Ganglion cyst & $\begin{array}{l}\text { NP improved; CM, gait improved but has numb- } \\
\text { ness in hands \& head }\end{array}$ \\
\hline 7 & $75, \mathrm{M}$ & $\mathrm{CM}$ & RA, pannus, basilar invagination & $\begin{array}{l}\text { Symptoms stable; patient also has chronic in- } \\
\text { flammatory demyelinating polyneuropathy }\end{array}$ \\
\hline 8 & $20, \mathrm{~F}$ & NP, SD & $\begin{array}{l}\text { Basilar invagination, Chiari malformation, } \\
\text { cat's eye syndrome }\end{array}$ & $\begin{array}{l}\text { SD resolved, NP improved; patient has head- } \\
\text { aches }\end{array}$ \\
\hline 9 & $7, \mathrm{~F}$ & NP, SD, CS & Basilar invagination, Chiari malformation & NP, SD resolved; CS improved \\
\hline
\end{tabular}

tween C1-2 fusion and occipitocervical fusion, as shown in Table 2. Some patients underwent fusion prior to the endonasal odontoidectomy, while others were immobilized with a halo brace and underwent fusion later. In 2 cases both procedures were performed on the same day. The 2 patients who underwent odontoid biopsy did not undergo fusion, and follow-up dynamic radiography demonstrated no macroinstability.

\section{Immediate Postoperative Outcome}

The mean operative time for the endonasal portion was $308 \pm 147$ minutes (range 117-500 minutes). Two-thirds of patients were extubated at the end of the procedure, with the remainder on the 1st postoperative day (POD). If immediate extubation is considered POD 0 , the mean time to extubation occurred on POD 0.3. The mean time to resumption of oral feeding in this series was POD 1. One patient resumed oral feeding on POD 1 but had a poor oral intake that required observation and encouragement. This patient resumed a full diet on POD 4, although the etiology of this delay was unclear since the patient did not have any mechanical limitations on POD 1.

\section{Treatment Complications}

There was one delayed posterior cervical wound infection, which occurred 1 month postoperatively. The patient was treated with antibiotics and had clinical and radiological resolution. Two patients had postoperative epistaxis which required additional nasal packing. There were no instances of CSF leak. No patients required reoperation. No patients had velopharyngeal insufficiency.

\section{Symptomatic Outcome}

All preoperative symptoms completely resolved in 2

TABLE 2. Operative details, outcomes, and complications

\begin{tabular}{|c|c|c|c|c|c|c|c|}
\hline $\begin{array}{l}\text { Case } \\
\text { No. }\end{array}$ & $\begin{array}{c}\text { Op } \\
\text { Detail }\end{array}$ & Op Adjuncts & $\begin{array}{l}\text { Op Time } \\
\text { (mins) }\end{array}$ & $\begin{array}{l}\text { Blood Loss } \\
\quad(\mathrm{ml})\end{array}$ & $\begin{array}{l}\text { Extubated } \\
\text { (POD) }\end{array}$ & $\begin{array}{l}\text { Oral Feed } \\
\text { (POD) }\end{array}$ & Complications \\
\hline 1 & ENB & No & 123 & & 1 & 1 & None \\
\hline 2 & ENR & $\mathrm{OCF}^{*}$ & 496 & 20 & 0 & 1 & Reduced oral intake-resolved Day 4 \\
\hline 3 & ENR & OCF† & 242 & 100 & 1 & 2 & None \\
\hline 4 & ENB & No & 117 & 20 & 0 & 0 & None \\
\hline 5 & ENR & Decompression \& OCF* & 376 & 40 & 0 & 1 & None \\
\hline 6 & ENR & C1-2 fusiont & $646 \ddagger$ & 20 & 1 & 1 & $\begin{array}{l}\text { Posterior wound infection; treated w/ } \\
\text { antibiotics, did not require reop }\end{array}$ \\
\hline 7 & ENR & C1-2 fusion* & 300 & 20 & 0 & 1 & Epistaxis \\
\hline 8 & ENR & Decompression \& OCF* & 500 & 25 & 0 & 1 & Epistaxis \\
\hline 9 & ENR & Decompression \& OCF* & 311 & 20 & 0 & 1 & None \\
\hline
\end{tabular}



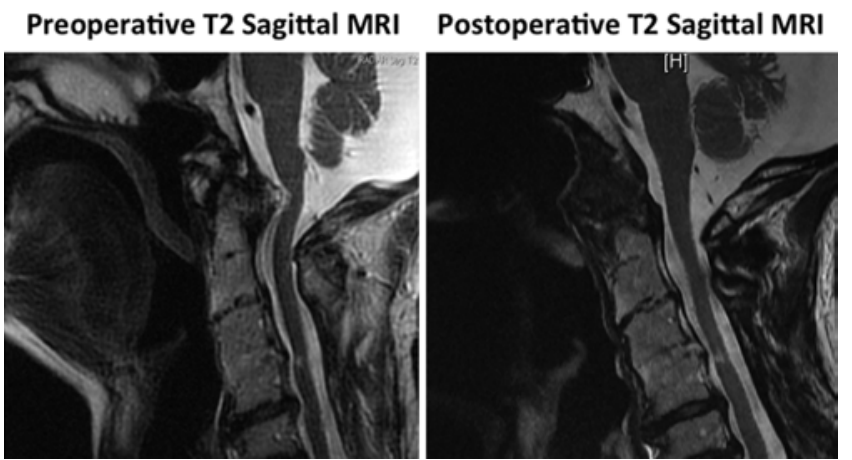

FIG. 2. Case 7. Example of pre- and postoperative midline sagittal T2weighted MR images. Note the increased T2 signal and CSF space ventral to the $\mathrm{CMJ}$, indicating successful radiological decompression.

patients, and a subset of symptoms completely resolved in another 3 patients (Table 1). All other patients showed improvement in all symptoms with the exception of the patient in Case 7, who had concurrent chronic inflammatory demyelinating polyneuropathy. Despite adequate radiographic decompression (Fig. 2), the patient had residual symptoms of gait disturbance and upper- and lower-extremity paresthesia. Those patients who underwent diagnostic biopsy reported resolution of their symptoms following institution of appropriate medical or adjuvant therapies.

\section{Radiographic Outcome}

Odontoidectomy resulted in a significant $(\mathrm{p}=0.03)$ spinal cord decompression as determined by a mean increase in T2 signal (or CSF space) on postoperative MRI of 2.34 $\pm 0.43 \mathrm{~mm}$ (range $1.72-3.03 \mathrm{~mm}$ ) (Table 3 and Fig. 3). One patient did not have an MR image available for comparison. For those patients in whom the goal of surgery was complete odontoidectomy, on postoperative CT there was complete resection in $57 \%$. The remaining patients had small, clinically insignificant fragments of bone always on the left side (Table 4 and Fig. 4).

\section{Discussion}

The traditional method for anterior decompression of CMJ abnormalities is the transoral approach. ${ }^{6,14,24}$ The transoral approach provides a direct midline route to the ventral CMJ. Because of the deep surgical corridor, the approach occasionally needs to be widened with transmandibular or transmaxillary extensions to improve the rostral and caudal limits of the exposure. ${ }^{4,17,31}$ Splitting of the soft palate and resection of the hard palate are often incorporated into the transoral approach to increase the exposure, particularly in patients with a small mouth. A recent review of the transoral approaches showed that a soft palate incision is used in $33.6 \%$ of cases. ${ }^{20}$ Postoperative complications secondary to the approach and its modifications include tongue edema and even necrosis, tracheal edema, hypernasal speech, and nasal regurgitation. ${ }^{20}$ As a result of such maneuvers and complications, the patient may need additional tracheostomy and gastrostomy that may lead to prolonged recovery and hospitalization. In
TABLE 3. Pre- and postoperative mean measurements (in $\mathrm{mm}$ ) of T2 signal (CSF space) ventral to the spinal cord at the level of the odontoid

\begin{tabular}{cccc}
\hline Case No. & Preop & Postop & Difference \\
\hline 1 & Biopsy & NA & NA \\
\hline 2 & 0.875 & 3.90 & 3.025 \\
\hline 3 & - & - & - \\
\hline 4 & Biopsy & NA & NA \\
\hline 5 & 0.25 & 2.075 & 1.825 \\
\hline 6 & 0 & 1.72 & 1.72 \\
\hline 7 & 0 & 2.40 & 2.40 \\
\hline 8 & 0.454 & 3.07 & 2.616 \\
\hline 9 & 0.015 & 2.65 & 2.635 \\
\hline
\end{tabular}

$\mathrm{NA}=$ not applicable $;-=$ not available.

fact, gastrostomy tubes were placed in roughly $14.8 \%$ of transoral cases in a recent review with a tracheostomy rate of $3.8 \%$, a $4 \%$ rate of velopharyngeal insufficiency, and a perioperative mortality rate of $2.3 \% .^{20}$

In contrast, the minimally invasive nature of the endonasal endoscopic approach aims to reduce these complications and comorbidities. To date there have been roughly 25 cases of endonasal endoscopic odontoid resection, most of which have been published as case reports. $3,10-13,18,19,21-23$, ${ }^{25-28,30}$ A recent review comparing transoral with endonasal odontoidectomy has shown that the average time to extubation and time to feeding in the currently published literature following transoral surgery is 3.5 and 5.2 days, respectively, compared with 0.43 and 3.86 days following endonasal endoscopic surgery. ${ }^{20}$ In our current paper, we report a series of 9 cases in which extubation and feeding occurred a mean of 0.3 and 1 day after surgery, respectively. These cases add significantly to the existing literature, not only in number of cases but also in demonstrating the rapidity with which patients can be extubated and fed after endonasal endoscopic odontoidectomy.

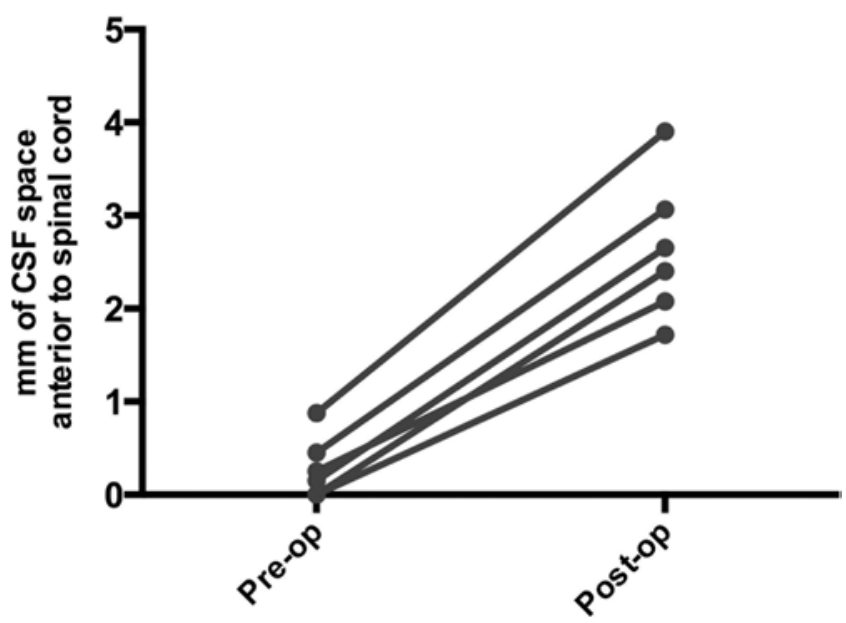

FIG. 3. Graph showing the measurement of the distance between the back of odontoid and front of CMJ before and after decompression based on MRI findings. Each line represents 1 patient. Images were not available in 1 patient. 
TABLE 4. Postoperative CT assessment of extent of odontoid resection

\begin{tabular}{cl}
\hline Case No. & \multicolumn{1}{c}{ CT Finding } \\
\hline 1 & Biopsy \\
\hline 2 & Complete resection \\
\hline 3 & Complete resection \\
\hline 4 & Biopsy \\
\hline 6 & Small fragment of bone on left \\
\hline 7 & Complete resection of cyst, rim of bone on left \\
\hline 8 & Small fragment of bone on left \\
\hline 9 & Complete resection \\
\hline
\end{tabular}

The largest single series of endonasal odontoidectomies published to date was by Nayak et al., ${ }^{25}$ who reported their experience in a series of 9 patients. Four of 9 patients required tracheostomy in the perioperative period, 3 required postoperative gastrostomy, and 2 developed transient velopharyngeal incompetence. Although the rate of these complications and comorbidities is higher than expected for the endonasal endoscopic approach, it should be noted that 4 of the 9 patients presented with dysphagia or respiratory failure preoperatively. In another prior series the authors inserted nasogastric tubes endoscopically at the time of surgery for postoperative feeding, reportedly to prevent infection. ${ }^{15}$ The results in our series demonstrate that even better results can be achieved, particularly in patients without preoperative dysphagia or respiratory failure, and that nasogastric tubes are not required to prevent infections.
With respect to extent of resection of the odontoid, a prior review demonstrated rates of $100 \%$ and $97 \%$ for the transoral and endonasal approaches, respectively. ${ }^{20}$ In the current paper, we did not specifically look at grosstotal resection of the odontoid since the odontoid is not a tumor and since the inferior extent of the resection is not clearly defined. For this reason, we developed a novel and more useful metric, namely the distance between the back of the odontoid and the front of the CMJ, consisting of high T2 signal on sagittal MRI, or the CSF space, to demonstrate the adequacy of achieving the anatomical goal of surgery. This metric correlated well with improvement in symptoms, which occurred in all patients except one whose symptoms were likely caused by chronic inflammatory demyelinating polyneuropathy. These results compare favorably with those reported in the literature for both transoral (73.3\% improvement) and endonasal (100\% improvement) surgery. ${ }^{20}$

Although we performed fusion in all patients in this series who underwent an odontoidectomy, rather than just a biopsy, prior reports have claimed that fusion may not be necessary after endonasal odontoidectomy. ${ }^{12}$ This was attributed to a reduction in instability due to the minimally invasive endonasal approach and preserving the C-1 arch. ${ }^{12}$ In our series, we have not been able to remove the odontoid adequately without removing the anterior ring of $\mathrm{C}-1$. However, there are likely patients whose spines may have already autofused who may not require an instrumented fusion. Indeed, in the transoral series by Choi and Crockard, fusion was also not always performed and its indication was dictated on a case-by-case basis. ${ }^{5}$

Although the transoral approach is still considered the gold standard, in light of the above findings, we believe that the endoscopic endonasal approach offers several dis-


\section{Pre-operative Sagittal}

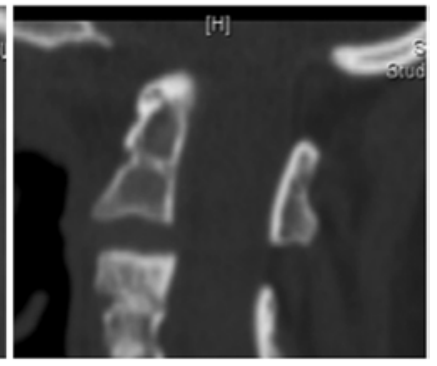

Post-operative
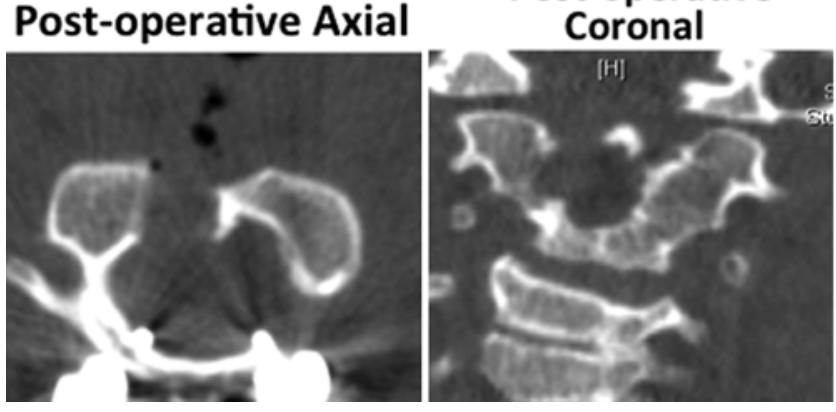

Post-operative Sagittal

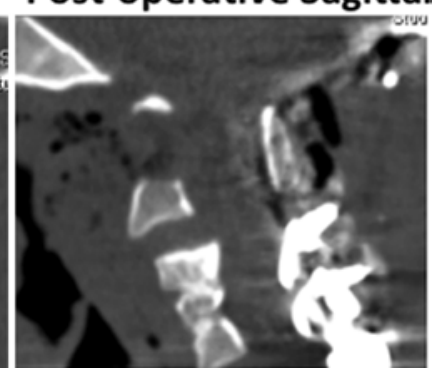

FIG. 4. Illustrative example of pre- and postoperative axial, coronal, and sagittal CT images demonstrating small residual fragment of bone on the left. 
tinct advantages. Endoscopic surgery brings vision and light directly to the surgical target. This allows for adequate visualization through a more limited corridor and exposure. In particular, the corridor being above the oropharynx reduces exposure to saliva, potentially decreasing wound infection and dehiscence. In addition, this permits reduced tracheal and glossal edema, offering the potential for faster extubation and tracheostomy avoidance, as well as more rapid reintroduction of oral feeding. Significantly, a proportion of patients with odontoid pathology may present with bulbar symptoms. In such cases, it is especially beneficial that the endonasal approach circumvents the oropharynx, avoiding further perturbation to swallowing mechanisms.

Despite these advantages, the endonasal approach is not always feasible. The endonasal corridor is limited laterally by the eustachian tubes, cranially by the nasal bones and nasal soft tissues, and caudally by the soft and hard palates. ${ }^{8}$ Crucially, the odontoid pathology or surgical target must be within these borders. When this is not the case, another approach is required either as an alternative or an adjunct to the endonasal approach. It has been suggested that the endonasal approach may be more useful for pathology located in the clival to upper odontoid region, whereas the transoral approach may be best suited to pathology located between the lower clivus to the body of $\mathrm{C}-2$ and the transcervical approach for pathology not involving the clivus. ${ }^{20}$ However, the transcervical route is not always feasible due to precluding factors such as obesity, barrel chests, or kyphotic deformities. ${ }^{7}$ The key determinant of approach viability will be the relative location of the odontoid to the back of the hard palate. The palatine line and nasopalatine angle have been shown to be important determinants in selecting the most appropriate candidates for the endonasal approach. ${ }^{8,9}$ When the endonasal approach is precluded, it may be combined with the transoral approach or the transoral approach can be used in isolation, or a transcervical approach can be entertained., ${ }^{1,7}$ The best approach therefore needs to be individualized for each case.

There are some important differences in the surgical technique used in this series from those previously reported. Others have advocated a wide opening of the sphenoid sinus. ${ }^{19}$ We have found that a minimal or even no sphenoidotomy is all that is required, mainly to provide familiar surgical landmarks. Others have concurred, with the exception of cases of severe basilar invagination, when a more rostral exposure is required. ${ }^{11}$ While all series use a binostril, 4-hand technique, we have found the endoscope holder to be a helpful adjunct in endonasal endoscopic cases in general. ${ }^{29}$ In the current series, this is no exception and it was introduced at the point at which the odontoid was reached. This is helpful to maintain a steady view and allow for an extra hand to assist if required. For these reasons we disagree that the endoscope holder limits the procedure, ${ }^{19}$ in fact, we believe it enhances the procedure. We used both a U-shaped flap in the nasopharyngeal mucosa as well as a linear incision and did not have any healing complications. A linear incision in the mucosa has been suggested as preferable and both are viable in our hands. ${ }^{12}$ Finally, we found that in spite of achieving an adequate anatomical decompression of the CMJ as well as symptomatic relief, it was not uncommon to find a small shell of residual odontoid on the left side, seen in $43 \%$ of patients. This finding is puzzling since a right-sided approach should direct the surgeon more to the left. However, since we generally place the scope in the left nostril, the field of view may favor the right side. These results indicate the importance of using intraoperative imaging, such as intraoperative CT scanning or the $\mathrm{O}$-arm, to ensure adequate bone decompression. Likewise, placing the scope in the right nostril at some point in the operation to reach the left side of the odontoid may reduce the incidence of residual bone fragments on the left.

\section{Limitations}

The study is limited by its small numbers and the fact that patients were reviewed retrospectively. While ideally a meaningful comparison with other approaches would be conducted by a randomized trial, due to small numbers and anatomical and pathological differences as well as inherent issues in surgical trial design, ${ }^{2}$ it is unlikely that such a trial will be conducted. We also wish to point out that 3 of these patients were previously published as case reports (Cases 1-3). ${ }^{10,21,22}$

\section{Conclusions}

This series of 9 cases of endonasal endoscopic odontoidectomy adds significantly to the existing literature not only in the number of cases compared to the small number already published, but in the results, which are markedly better than those of previous reports. Although this is a small case series, these cases suggest that there are advantages of the endonasal endoscopic approach in permitting early extubation, early feeding and minimizing complications compared with transoral surgery. We hope that additional cases from other centers will further substantiate our claims.

\section{References}

1. Baird CJ, Conway JE, Sciubba DM, Prevedello DM, Quiñones-Hinojosa A, Kassam AB: Radiographic and anatomic basis of endoscopic anterior craniocervical decompression: a comparison of endonasal, transoral, and transcervical approaches. Neurosurgery 65 (6 Suppl):158-164, 2009

2. Bandopadhayay P, Goldschlager T, Rosenfeld JV: The role of evidence-based medicine in neurosurgery. J Clin Neurosci 15:373-378, 2008

3. Beech TJ, McDermott AL, Kay AD, Ahmed SK: Endoscopic endonasal resection of the odontoid peg-case report and literature review. Childs Nerv Syst 28:1795-1799, 2012

4. Bhangoo RS, Crockard HA: Transmaxillary anterior decompressions in patients with severe basilar impression. Clin Orthop Relat Res (359):115-125, 1999

5. Choi D, Crockard HA: Evolution of transoral surgery: three decades of change in patients, pathologies, and indications. Neurosurgery 73:296-304, 2013

6. Crockard HA: Transoral surgery: some lessons learned. Br J Neurosurg 9:283-293, 1995

7. Dasenbrock HH, Clarke MJ, Bydon A, Sciubba DM, Witham TF, Gokaslan ZL, et al: Endoscopic image-guided transcervical odontoidectomy: outcomes of 15 patients with basilar invagination. Neurosurgery 70:351-360, 2012 
8. de Almeida JR, Zanation AM, Snyderman CH, Carrau RL, Prevedello DM, Gardner PA, et al: Defining the nasopalatine line: the limit for endonasal surgery of the spine. Laryngoscope 119:239-244, 2009

9. El-Sayed IH, Wu JC, Dhillon N, Ames CP, Mummaneni P: The importance of platybasia and the palatine line in patient selection for endonasal surgery of the craniocervical junction: a radiographic study of 12 patients. World Neurosurg 76:183-188, 74-78, 2011

10. Fraser JF, Anand VK, Schwartz TH: Endoscopic biopsy sampling of tophaceous gout of the odontoid process. Case report and review of the literature. J Neurosurg Spine 7:61-64, 2007

11. Gempt J, Lehmberg J, Grams AE, Berends L, Meyer B, Stoffel M: Endoscopic transnasal resection of the odontoid: case series and clinical course. Eur Spine J 20:661-666, 2011

12. Gladi M, Iacoangeli M, Specchia N, Re M, Dobran M, Alvaro L, et al: Endoscopic transnasal odontoid resection to decompress the bulbo-medullary junction: a reliable anterior minimally invasive technique without posterior fusion. Eur Spine J 21 (Suppl 1):S55-S60, 2012

13. Grammatica A, Bonali M, Ruscitti F, Marchioni D, Pinna G, Cunsolo EM, et al: Transnasal endoscopic removal of malformation of the odontoid process in a patient with type I Arnold-Chiari malformation: a case report. Acta Otorhinolaryngol Ital 31:248-252, 2011

14. Hadley MN, Spetzler RF, Sonntag VKH: The transoral approach to the superior cervical spine. A review of 53 cases of extradural cervicomedullary compression. J Neurosurg 71:16-23, 1989

15. Han S, Ding X, Tie X, Liu Y, Xia J, Yan A, et al: Endoscopic endonasal trans-sphenoidal approach for pituitary adenomas: is one nostril enough? Acta Neurochir (Wien) 155:16011609,2013

16. Hsu W, Wolinsky JP, Gokaslan ZL, Sciubba DM: Transoral approaches to the cervical spine. Neurosurgery 66 (3 Suppl):119-125, 2010

17. Kanamori Y, Miyamoto K, Hosoe H, Fujitsuka H, Tatematsu N, Shimizu K: Transoral approach using the mandibular osteotomy for atlantoaxial vertical subluxation in juvenile rheumatoid arthritis associated with mandibular micrognathia. J Spinal Disord Tech 16:221-224, 2003

18. Kassam AB, Abla A, Snyderman C, Carrau R, Spiro R: An endoscopic transnasal odontoidectomy to treat cervicomedullary compression with basilar invagination. Op Tech Neurosurg 8:198-204, 2005

19. Kassam AB, Snyderman C, Gardner P, Carrau R, Spiro R: The expanded endonasal approach: a fully endoscopic transnasal approach and resection of the odontoid process: technical case report. Neurosurgery 57:E213, 2005

20. Komotar RJ, Starke RM, Raper DMS, Anand VK, Schwartz TH: Endoscopic endonasal versus open transcranial resection of anterior midline skull base meningiomas. World Neurosurg 77:713-724, 2012

21. Laufer I, Greenfield JP, Anand VK, Härtl R, Schwartz TH: Endonasal endoscopic resection of the odontoid process in a nonachondroplastic dwarf with juvenile rheumatoid arthritis: feasibility of the approach and utility of the intraoperative Iso-C three-dimensional navigation. Case report. J Neurosurg Spine 8:376-380, 2008
22. Leng LZ, Anand VK, Hartl R, Schwartz TH: Endonasal endoscopic resection of an os odontoideum to decompress the cervicomedullary junction: a minimal access surgical technique. Spine (Phila Pa 1976) 34:E139-E143, 2009

23. Magrini S, Pasquini E, Mazzatenta D, Mascari C, Galassi E, Frank G: Endoscopic endonasal odontoidectomy in a patient affected by Down syndrome: technical case report. Neurosurgery 63:E373-E374, 2008

24. Menezes AH, VanGilder JC: Transoral-transpharyngeal approach to the anterior craniocervical junction. Ten-year experience with 72 patients. J Neurosurg 69:895-903, 1988

25. Nayak JV, Gardner PA, Vescan AD, Carrau RL, Kassam AB, Snyderman $\mathrm{CH}$ : Experience with the expanded endonasal approach for resection of the odontoid process in rheumatoid disease. Am J Rhinol 21:601-606, 2007

26. Patel AJ, Boatey J, Muns J, Bollo RJ, Whitehead WE, Giannoni CM, et al: Endoscopic endonasal odontoidectomy in a child with chronic type 3 atlantoaxial rotatory fixation: case report and literature review. Childs Nerv Syst 28:1971-1975, 2012

27. Rawal RB, Shah RN, Zanation AM: Endonasal odontoidectomy for basilar impression and brainstem compression due to radiation fibrosis. Laryngoscope 123:584-587, 2013

28. Scholtes F, Signorelli F, McLaughlin N, Lavigne F, Bojanowski MW: Endoscopic endonasal resection of the odontoid process as a standalone decompressive procedure for basilar invagination in Chiari type I malformation. Minim Invasive Neurosurg 54:179-182, 2011

29. Schwartz TH, Anand VK: The endoscopic endonasal transsphenoidal approach to the suprasellar cistern. Clin Neurosurg 54:226-235, 2007

30. Sinha S, Mirza S, Bishop N, Zaki H, McMullan J: Endoscopic endonasal resection of the odontoid peg for paediatric basilar invagination. Br J Neurosurg 26:487-489, 2012

31. Vishteh AG, Beals SP, Joganic EF, Reiff JL, Dickman CA, Sonntag VKH, et al: Bilateral sagittal split mandibular osteotomies as an adjunct to the transoral approach to the anterior craniovertebral junction. Technical note. J Neurosurg 90 (2 Suppl):267-270, 1999

\section{Author Contributions}

Conception and design: Schwartz. Acquisition of data: all authors. Analysis and interpretation of data: Schwartz, Goldschlager. Drafting the article: Schwartz, Goldschlager. Critically revising the article: Schwartz, Goldschlager. Reviewed submitted version of manuscript: all authors. Approved the final version of the manuscript on behalf of all authors: Schwartz. Statistical analysis: Schwartz, Goldschlager. Administrative/technical/material support: Schwartz. Study supervision: Schwartz.

\section{Correspondence}

Theodore H. Schwartz, Department of Neurosurgery, Weill Cornell Medical College, NewYork-Presbyterian Hospital, 525 E. 68th St., Box 99, New York, NY 10065. email: schwarh@med. cornell.edu. 